\title{
Prevalence and detecting spatial clustering of anaemia among children 6-59 months in the districts of India
}

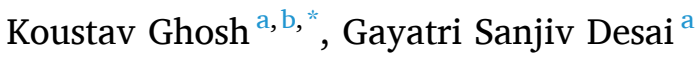 \\ a Population Research Centre (PRC), Baroda, Department of Statistics, Faculty of Science,The Maharaja Sayajirao University of Baroda, Vadodara, Gujarat, India \\ ${ }^{\mathrm{b}}$ PhD Research Scholar, Gokhale Institute of Politics and Economics (GIPE), Pune, Maharashtra, India
}

\section{A R T I C L E I N F O}

\section{Keywords:}

Auto-correlation

Clustering

Hot-spot

Moran's I

Underweight children

\begin{abstract}
A B S T R A C T
Background: Among the developing countries, India was the largest contributor to child anaemia in the last decade. It has many harmful effects on children's lifestyle as it reduces learning capacity, attentiveness and intelligence. The study attempts to identify the spatial prevalence and detect the clustering of anaemia in India based on National Family Heath Survey-IV, 2015-16 and also tries to identify the determinants of anaemia among children (6-59 months).

Methods: The study uses spatial analysis software ArcGIS 10.8 and GeoDa1.18 including Moran's index. Logistic regression model is applied by using STATA-14, to assess the effects of socio-economic and demographic, maternal and child characteristic predictors of prevalence of anaemia among children.

Results: The anaemia prevalence is highest in Dadra \& Nagar Haveli and lowest in Meghalaya. A total of 321 districts are having more than the national level average $(58.65 \%)$ of anaemia. Study also finds 110 districts as the hot-spot areas (Moran's I = 0.63) mostly from central, western, south-western, northern and eastern parts of India. Increase of mother's age, education, receipt of full ANC and richer wealth quantile reduce the risk of childhood anaemia. On the other hand, underweight mothers, children in the age group 12-23 months, underweight children and higher birth order increase the risk of childhood anaemia.

Conclusion: The study suggests targeting the hot-spot districts with a high prevalence of anaemia and policy-level interventions addressing micronutrient deficiency like the Integrated Child Development Scheme, to reduce the risk of childhood anaemia.
\end{abstract}

\section{Introduction}

As high as 1.9 billion i.e. $27 \%$ of the world's population were leaving with the burden of anaemia in 2013 (haemoglobin level $<11.0 \mathrm{~g} / \mathrm{dL}$ ) and developing countries accounted for more than $89 \%$ of this burden. ${ }^{1}$ Around 90,000 maternal and neonatal deaths were due to iron deficiency anaemia in the developing regions in $2013 .{ }^{2}$ Currently, the Global Nutrition Report has noted a total of 125 countries to be facing the burden of anaemia; 52 countries facing a double burden i.e. of anaemia along with overweight whereas 38 countries are reported to be facing a dual burden of stunting and anaemia. ${ }^{3}$

An estimated $50 \%$ of people were suffering from anaemia in the South East Asia region, and about half of the cases were caused by iron deficiency. ${ }^{2}$ Such type of anaemia is still a very common problem in South Asian countries, including India, Bangladesh and Pakistan. It causes major serious problems, especially among pregnant and lactating women, children and adolescents. ${ }^{4}$ Studies on anaemia in low-income and middle-income countries have focused on women of reproductive age and their children because anaemia during pregnancy and early childhood is associated with important adverse effects for the child-including low birth weight, ${ }^{5}$ poor mental and motor development, ${ }^{6}$ and mortality ${ }^{7}$ and for the mother-particularly maternal mortality. ${ }^{7}$ Hence it is one of the top ten risk factors in the world. ${ }^{8}$ Anaemia has been a major public health issue in developing countries like India.

Among the developing countries, India was the largest contributor to childhood anaemia in the last decade $\mathrm{e}^{9,10}$ and Economic Action Group (EAG) states contribute about $70 \%$ of anaemic children in the country. ${ }^{11}$ In case of pre-school children anaemia is the result of lack of nutritional intake of iron, folates, vitamin A, B12 and micro-nutrients and malaria infection. ${ }^{10,12,13}$ Studies show that it has many harmful effects on

\footnotetext{
* Corresponding author. Population Research Centre (PRC), Baroda, Department of Statistics, Faculty of Science,The Maharaja Sayajirao University of Baroda, Vadodara, Gujarat, India.

E-mail addresses: koustav.ghosh-prc@msubaroda.ac.in (K. Ghosh), desai.gayatri-prc@msubaroda.ac.in (G.S. Desai).
} 
children's lifestyle as it reduces learning capacity, attentiveness and intelligence. ${ }^{14-17}$ Childhood anaemia was found to be a severe public health problem irrespective of urban residence, better wealth status and educational levels. ${ }^{18}$ A study by Bharati et al. in 2020 based on NFHS-4 suggests that improved socio-economic status of a household helps to reduce the risk of childhood anaemia whereas low birth weight and poor maternal nutrition status increase the risk of childhood anaemia in India. ${ }^{19}$

Literature shows that low household income, less maternal education, mother's anaemic status etc. are responsible for high prevalence of anaemia in India. ${ }^{20}$ Furthermore, the children from rural areas need to be paid higher attention as they are living with higher risk of anaemia. Mother's education, nutrition, and birth control measures may reduce the risk of anaemia. ${ }^{21}$

The National Family Health Survey estimated that $58 \%$ of children age 6-59 months were anaemic in India (haemoglobin levels below 11.0 $\mathrm{g} / \mathrm{dL}$ ), an improvement over the NFHS-3 estimate of $70 \% .^{22}$

The issue of childhood anaemia has bben one of the major public health challenges in India since many years. It has many harmful effects on children's lifestyle as it reduces learning capacity, attentiveness and intelligence. Despite the economic development and the national anaemia control programme there was no major reduction in the rate of anaemia in India. The prevalence of anaemia among under five children has reduced by only $11 \%$ from 2005 to 06 to $2015-16 .^{23}$

A geospatial analysis along with risk factors of childhood anaemia in India will help to reduce the burden of anaemia. In view of this the present study has attempted to determine the prevalence and detect the spatial clustering of anaemia among children (6-59 Months) across the districts of India. The study also aims to examine the associated risk factors for childhood anaemia in India. Hence the study tries to identify the high prevalence and hot-spot districts along with the factors which may help in decline of this morbid condition among children in India.

\section{Materials and methods}

\subsection{Data source}

The present study is based on the data from the National Family Health Survey (NFHS-4) conducted in the year 2015-16 in India. NFHS4 had covered 35 states/UTs including 640 districts in the country. ${ }^{23}$ This all-India survey was conducted under the supervision of the Ministry of Health \& Family Welfare, Government of India with International Institute for Population Sciences (IIPS), Mumbai, being the nodal agency. Multistage stratified sampling design has been used for the survey and it provides the estimation of clinical, anthropometric and biochemical $(\mathrm{CAB})$ components along with the prevalence of diabetes, hypertension, malnutrition and HIV through the biometric measurements.

In NFHS, 2015-16 haemoglobin testing was performed on all children aged 6-59 months in the sample households using capillary blood. As per the standards of NFHS, children were considered as anaemic when their haemoglobin level was below $11.0 \mathrm{~g} / \mathrm{dL}$; as mildly anaemic with 10.0-10.9 g/dL, moderately anaemic with 7.0-9.9 g/dL and as severely anaemic with less than $7.0 \mathrm{~g} / \mathrm{dL}$. The total sample size utilised for the study was of 209495 .

\subsection{Methodology}

To understand the geographical variation and detect spatial clustering of child anaemia across the districts of India, the study has used spatial analysis software ArcGIS 10.8 and GeoDa. To determine the existence of clustering, spatial heterogeneity and spatial auto-correlation in prevalence of anaemia, Exploratory Spatial Data Analysis (ESDA) has been attempted. Geographical Information System (GIS) and spatial statistical technique based on ESDA are useful in describing and representing spatial distribution, detecting hot-spot and cold-spot areas and
Table 1

Prevalence of Children Anaemia (6-59 Months) by gender in the State/UTs in India, NFHS 2015-16.

\begin{tabular}{|c|c|c|c|c|}
\hline \multirow[t]{3}{*}{ State/UTs } & \multicolumn{4}{|c|}{ Anaemia Prevalence (in percentage) } \\
\hline & \multicolumn{2}{|c|}{ Gender } & \multirow[t]{2}{*}{ Total } & \multirow[t]{2}{*}{ Total Sample Size } \\
\hline & Male & Female & & \\
\hline Andaman \& Nicobar Islands & 54.55 & 44.89 & 50.27 & 44 \\
\hline Andhra Pradesh & 56.66 & 60.5 & 58.5 & 6407 \\
\hline Arunachal Pradesh & 53.92 & 54.87 & 54.38 & 162 \\
\hline Assam & 36.06 & 35.67 & 35.88 & 4952 \\
\hline Bihar & 62.13 & 65.04 & 63.54 & 26772 \\
\hline Chandigarh & 63.55 & 81.98 & 72.18 & 121 \\
\hline Chhattisgarh & 41.83 & 41.64 & 41.74 & 4992 \\
\hline Dadra \& Nagar Haveli & 87.5 & 81.18 & 84.35 & 59 \\
\hline Daman \& Diu & 77.44 & 71.57 & 74.46 & 20 \\
\hline NCT Of Delhi & 49.43 & 47.25 & 48.35 & 192 \\
\hline Goa & 64.02 & 60.56 & 62.4 & 8617 \\
\hline Gujarat & 70.56 & 73.36 & 71.84 & 4921 \\
\hline Haryana & 52.12 & 55.4 & 53.7 & 922 \\
\hline Himachal Pradesh & 53.38 & 55.01 & 54.16 & 1877 \\
\hline Jammu \& Kashmir & 69.06 & 71.22 & 70.1 & 6334 \\
\hline Jharkhand & 61.53 & 60.95 & 61.25 & 8545 \\
\hline Karnataka & 35.29 & 36.58 & 35.95 & 3760 \\
\hline Kerala & 50.79 & 54.82 & 52.61 & 10 \\
\hline Lakshadweep & 69.2 & 68.83 & 69.02 & 14507 \\
\hline Madhya Pradesh & 54.21 & 53.7 & 53.97 & 17660 \\
\hline Maharashtra & 25.92 & 21.88 & 23.96 & 428 \\
\hline Manipur & 48.25 & 48.03 & 48.14 & 626 \\
\hline Meghalaya & 21.1 & 18.04 & 19.63 & 183 \\
\hline Mizoram & 26.36 & 26.83 & 26.59 & 264 \\
\hline Nagaland & 61.49 & 57.72 & 59.86 & 1971 \\
\hline Odisha & 44.27 & 44.97 & 44.61 & 6950 \\
\hline Puducherry & 40.98 & 49.53 & 44.9 & 192 \\
\hline Punjab & 58.08 & 55.04 & 56.69 & 3666 \\
\hline Rajasthan & 60.46 & 60.41 & 60.44 & 12529 \\
\hline Sikkim & 59.01 & 51.36 & 55.54 & 51 \\
\hline Tamil Nadu & 51.65 & 49.86 & 50.77 & 12454 \\
\hline Telangana & 49.67 & 46.72 & 48.23 & 481 \\
\hline Tripura & 63.34 & 63.36 & 63.35 & 37409 \\
\hline Uttar Pradesh & 58.13 & 62.54 & 60.21 & 1699 \\
\hline Uttarakhand & 52.23 & 56.79 & 54.47 & 14346 \\
\hline West Bengal & 62.07 & 58.88 & 60.63 & 5373 \\
\hline India & 58.49 & 58.83 & 58.65 & 209495 \\
\hline
\end{tabular}

suggesting spatial regimes or other forms of spatial heterogeneity. ${ }^{24}$ For hot-spot analysis in GIS or Geo-Da a scale is important to specify the distance value. ${ }^{25}$ The computation of spatial autocorrelation requires the construction on the bases of matrix known as spatial weight matrix (W). The study has made use of Moran's I (spatial autocorrelation) and Local Indicators of Spatial Autocorrelation (LISA) to measure the extent of autocorrelation among the neighbourhood districts in the country. Moran's I helps in measuring the intensity of clustering (Z-score) with increasing distance. Furthermore, LISA statistics has been applied to detect the hot-spot areas across a district considering the percentage of children suffering from anaemia. The LISA values consent the computation of its similarity with its neighbouring districts and also test the level of significance ( $p$ values) for each location. LISA map portrays results in five scenarios-cluster with high values (high-high or hot spot), cluster with low values (low-low or cold spot), outlier in which a high value is surrounded by a low value (high-low), outliers wherein a low value is surrounded by a high value (low-high) and lastly no significant local autocorrelation.

To establish the relationship between prevalence of anaemia and it's contextual determinants, the study has applied the Logistic regression model by using STATA-14. Based on the above literature review and previous research, the study has used the explanatory variables.

Outcome variable: The study has used prevalence of anaemia among children as the dependent variable. This study variable is dichotomous with 1 considered as "Anaemic" and 0 considered as "Not Anaemic".

Independent Variables: A set of background characteristics of the households along with factors associated with child and mother have 


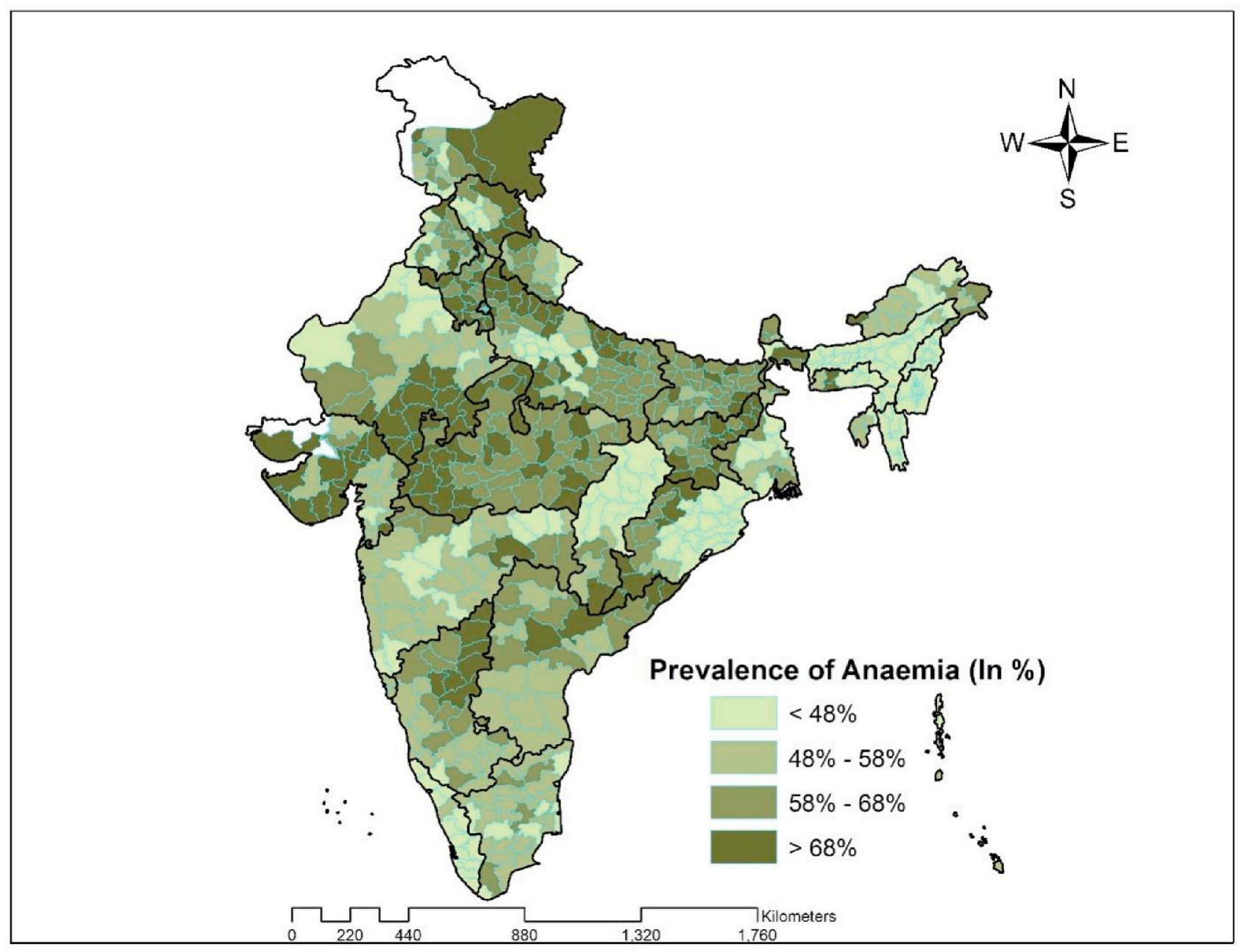

Fig. 1. Spatial Prevalence of Anaemia among children (6-59 Months) in India (2015-16): A district level map.

been used based on existing literature and availability of data. Residence, religion, caste, wealth quintile, regions have been taken as key background characteristics having implications for the variation in the prevalence of anaemia among children. Similarly, age of mother, education of mother, mother's anaemia status (haemoglobin level below $12.0 \mathrm{~g} / \mathrm{dL}$ considered as anaemic and a level equal to or more than 12.0 $\mathrm{g} / \mathrm{dL}$ as not anaemic), mother's nutritional status/BMI (Body Mass Index), and number of ANC (Antenatal Care) while pregnant have been used as maternal factors in the study. Factors related to children included age of the child, sex of the child, experience of Diarrhoea (in last 2 weeks), birth order, nutritional status (Underweight).

\section{Results}

\subsection{Prevalence of Anaemia among children (6-59 Months) with geographical variation}

Table 1 represents the geographical variation of anaemia among children under-five years of age at the state/UT level in India (2015-16). At the national level, the prevalence of anaemia has been found to be $58.65 \%$. Looking to the gender differentials, about $58.49 \%$ of the male children and $58.83 \%$ of the female children are observed to be living with anaemia.

Among the different states/UTs of India, fourteen states/UTs show more than the national average of anaemia prevalence. The prevalence of anaemia is high in Dadra \& Nagar Haveli $(84.35 \%)$ followed by Daman \& Diu (74.46 \%), Chandigarh (72.18 \%), Gujarat (71.84 \%),
Jammu \& Kashmir (70.1 \%). On the other hand, Meghalaya (19.63\%), Maharashtra (23.96 \%), Mizoram (26.59\%), Assam (23.88\%), and Karnataka (35.95 \%) reported a low level of anaemia among children. Among males, the prevalence of anaemia ranged from the lowest in the state of Meghalaya (21.1\%) to highest in the UT of Dadra \& Nagar Haveli (87.5\%). Contrastingly, among females the range is from $18.5 \%$ (Meghalaya) to $81.95 \%$ (Chandigarh).

Fig. 1 illustrates the spatial prevalence of anaemia across the districts (total 640) of India. More than half of the districts i.e. 321 out of the 640 districts of the country have reported more than the national average of prevalence of childhood anaemia (58.65\%). Looking to spatial variance, the map (Fig. 1) shows that 164 districts have reported $<48 \%$ prevalence level of anaemia and 316 districts reported the level of anaemia ranging from $48 \%$ to $68 \%$; the remaining 160 districts reported $>68 \%$ prevalence of anaemia in the year 2015-16. Leh district (prevalence level $95.8 \%$ ) from Jammu \& Kashmir and Lahul and Spiti districts (prevalence level $94.85 \%$ ) from Himachal Pradesh show the highest prevalence of anaemia whereas the Champhai (7.87 \%) and Aizwal (11.05 \%) districts in Mizoram and Mokokchung (12.96 \%) in Nagaland represent a low level of anaemia prevalence. The high prevalence districts come from central, south-west, northern and eastern parts of India mostly from Uttar Pradesh, Madhya Pradesh, Jharkhand, Bihar, Uttarakhand, Gujarat, Karnataka, Haryana, Panjab, and Jammu\& Kashmir.

\subsection{Spatial clustering of anaemia in districts of India}

Moran's Index statistics of spatial autocorrelation shows the 


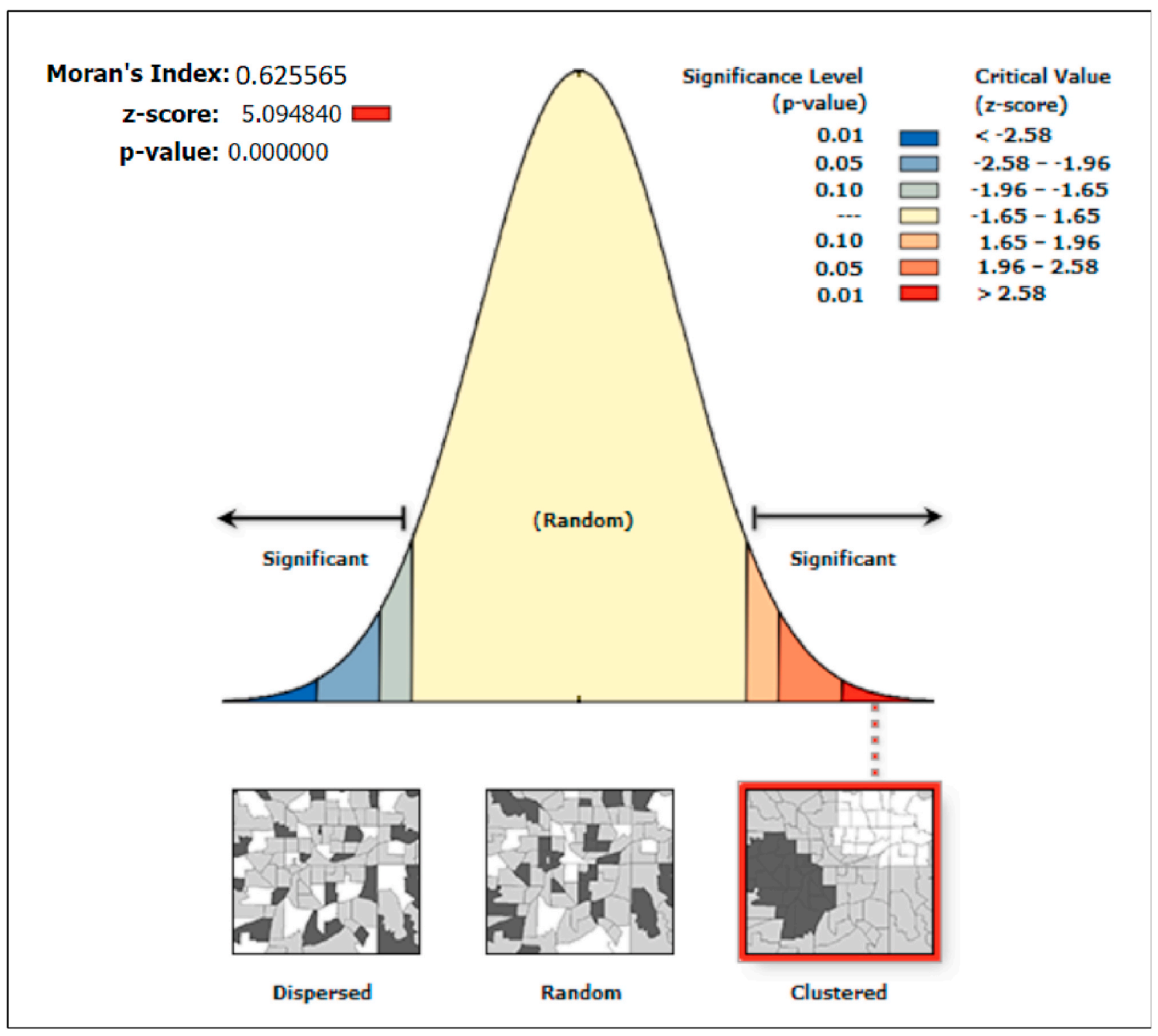

Fig. 2. Graphical presentation of the result of spatial autocorrelation of anaemia prevalence among children (6-59 months) in districts of India, 2015-16. A. LISA cluster map B. LISA significance map.

prevalence of anaemia in the districts of India as a cluster (Moran's Index is 0.63 ) and the results are also highly significant ( $\mathrm{p}$ value $<.001$ ) (Fig. 2). Based on this result, the LISA map has identified the probable hot-spot areas of childhood anaemia prevalence at the district level in India (depicted in Fig. 3). In Fig. 3, map A presents the clustering levels in the prevalence of anaemia, and map B depicts the significant levels of clustering. The hot spots (high to high) are shown in red colour indicating that districts with a higher prevalence of anaemia are surrounded by neighbouring districts with greater levels of anaemia. Contrarily, cold spots (low to low), given in blue colour, are the districts with lower levels of anaemia prevalence which also have similar neighbourhoods. A total of 110 districts belong to the hot-spot (cluster with high anaemia prevalence) areas which are mostly from central and northern parts of India.. Whereas 89 districts are from cold-spot areas from the south, and north-east and some are from central parts of India. The level of significance map represents that around 105 districts are reported in cluster with less than $5 \%$ significance level.
3.3. Prevalence of childhood anaemia (6-59 Months) with background characteristics

As indicated by Table 2, the prevalence of anaemia among children under 5 years was relatively higher among the urban residents as compared to their rural counterpart; it was the lowest among Christians (59\% each). The SC/ST group showed the highest percentage of such children (62\%). The economic factor showed the results in the expected direction with the highest percentage of such children belonging to the poor class. The regional variations ranged from the lowest i.e. $37 \%$ of anaemic children reported in the North East to the highest i.e. $63 \%$ from Central India.

Furthermore, anaemia prevalence was the highest among the children of very young mothers i.e. whose current age was $<25$ years $(62 \%)$ and illiterate mothers (65\%). Additionally, mothers who were anaemic also had a much higher percentage of anaemic children (65\%) as compared to those children (51\%) whose mothers were not anaemic. Similarly, the study shows that prevalence of anaemia is relatively higher among children whose mothers are thin (63\%) and mothers who had not received full ANC (60\%). 


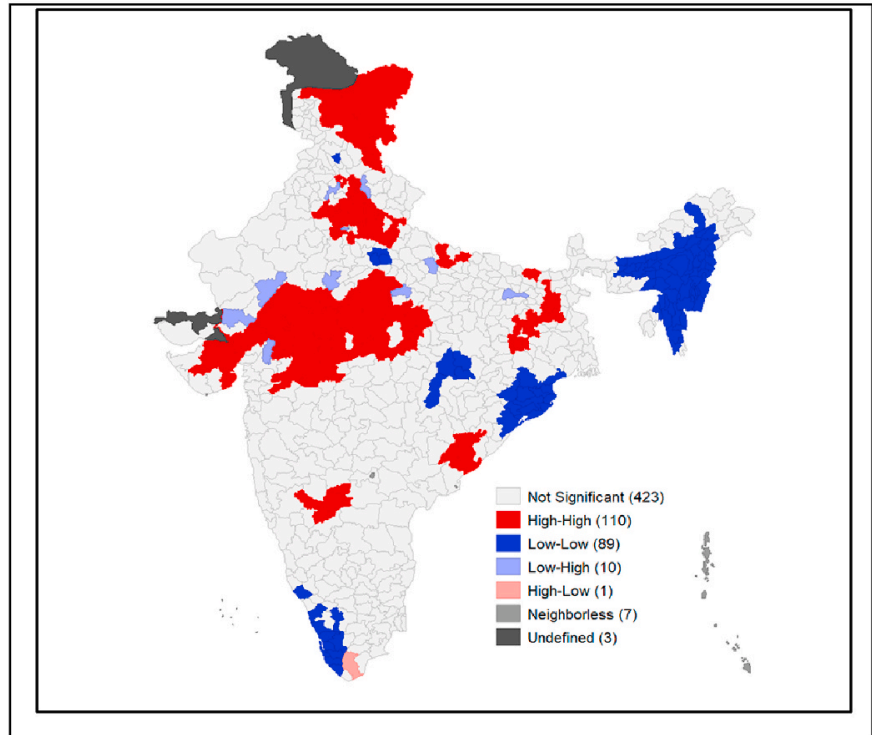

A. LISA cluster map

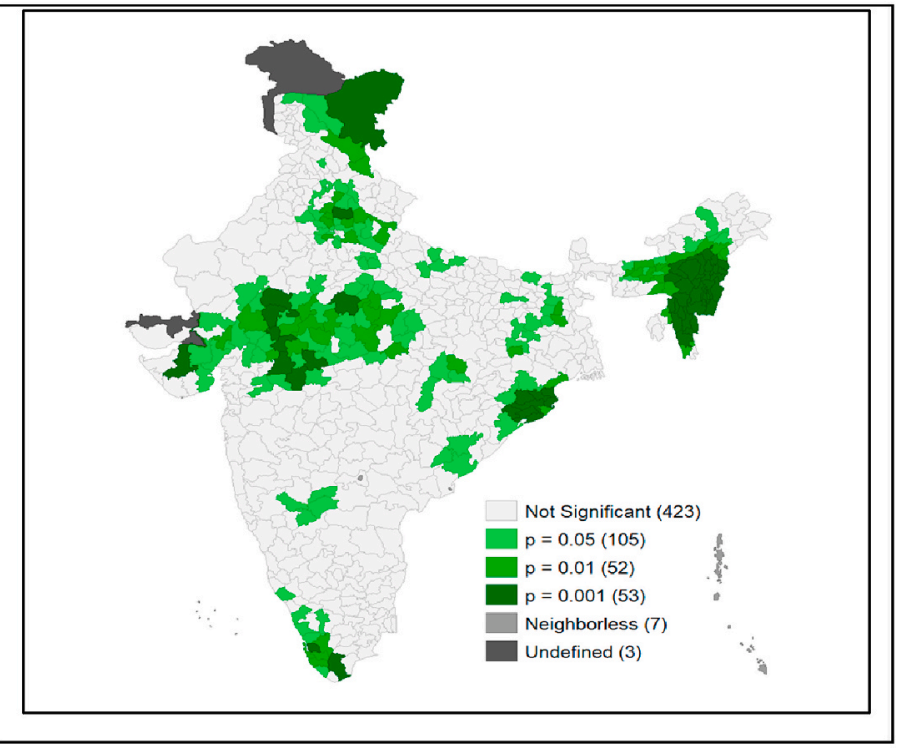

B. LISA significance map

Fig. 3. LISA cluster and LISA significance map of anaemia disease in Districts of India, 2015-16.

The anaemic condition of children improved with advancement in age. Hence anaemia is the lowest among the age group of 36-59 months. Anaemia also shows relation with diarrhoea as it is higher (65\%) among children who also had diarrhoea. Similarly, anaemia prevalence is more among the underweight children (63\%) and is the highest among the children who belonged to the third and above birth order (63\%).

\subsection{Childhood anaemia among children (6-59 Months) and its contextual determinants in India}

Among socio-economic variables, (Table 3) the odds of children suffering from anaemia is 1.12 times more likely among Muslims and less likely among Christians (OR:0.83; CI:0.78,0.89) as compared to Hindus. The children from OBC (OR: 0.88; CI: 0.85, 0.91) and Others social groups (OR: 0.82; CI: $0.79,0.85$ ) have a lesser chance of having anaemia as compared to SC/ST group. Children of rich quintile households are markedly less likely to experience anaemia (OR: 0.88; CI: $0.84,0.91$ ) as compared to poor household children. Children from East (OR: 0.71; CI:0.68,0.74), North-east (OR:0.36; CI:0.34, 0.38), Central (OR:0.92; CI: 0.88,0.96), West (OR:0.79; CI: 0.75,0.84) and south (OR:0.76; CI: 0.72,0.79) region of India are less likely to suffer from anaemia as compared to those from northern region.

Among the maternal characteristics, (Table 3) with increasing age of the mother, the probability of suffering from anaemia gets reduced. Primary (OR: 0.88; CI: 0.84, 0.93) and higher level (OR: 0.77; CI: 0.74, 0.80 ) educated mothers are less likely to be associated with children's anaemia as compared to illiterate mothers. Anaemic mothers increase the risk of children's anaemia by 1.81 times. Normal (OR:0.94; CI: $0.91,0.97$ ) and overweight (OR: 0.91; CI: 0.87; 0.95) mothers are less likely to be associated with children's anaemia as compared to thin mothers. Full antenatal care reduces the risk of childhood anaemia.

In case of children's characteristics, (Table 3) children age 12-23 months (OR:1.09; CI: 1.05,1.14) are more likely and those with 24-35 months (OR: 0.7; CI:0.67,0.73) and 36-59 months (OR: 0.42; CI:0.40,0.44) are less likely to be associated with anaemia as compared to 6-11 months' children. In case of children's nutritional status, underweight children have a higher risk of anaemia as compared to normal children. An increasing birth order increases the risk of anaemia.

\section{Discussion}

In India around $58.65 \%$ of children less than 5 years are living with anaemia in 2015-16, and girl's children are suffering more from anaemia as compared to male children. The prevalence is highest in the Union territories Dadra \&Nagar Haveli and Daman \& Diu. The reason for this is not clear, but it might be due to an improper diet, ${ }^{26}$ childhood illness such as diarrhoea, ${ }^{27}$ worm infestations ${ }^{28}$ or lack of appropriate iron supplementation. ${ }^{29}$ On the other hand, Meghalaya (19.63\%) and Maharashtra (23.69 \%) show a low level of anaemia among 6-59 months of children.

The present study reveals a remarkable geographical variation (ranging from the lowest in the state of Meghalaya i.e. 21.1\% to the highest in the UT of Dadra \& Nagar Haveli i.e. 87.5 \%) in the risk of childhood anaemia in the districts of India. The study finds that the prevalence of anaemia is the highest in central, south-west, and northern and eastern parts of India. Around $52 \%$ of districts are having more than the national level of anaemia disease. The study also finds the medium to high level of clustering of anaemia in the districts with 0.63 Moran's Index, which means auto-correlation exists between neighbourhood districts in India. ${ }^{12}$ Total 110 districts have been identified as hot-spot areas from central, eastern, northern and western parts of India and 105 districts show $<0.05 \%$ level of significance.

Among the socio-economic variables, children from Muslim religious background are more likely and those from Christian community are less likely to suffer from anaemia. ${ }^{19}$ Regarding the household wealth index, children from the richer households were less likely to suffer from this morbid condition as compared to those from the poor households. ${ }^{30}$ Among the social groups OBC and Others caste group are at a lesser risk as compared to SC/ST caste group. Children from northern part of India are at the higher risk as compared to other regions.

As regards the maternal characteristics, the increase in mother's age, ${ }^{12,30,32,37}$ education ${ }^{19,21,30-33,35,36}$ and receipt of full ANC reduce the risk of childhood anaemia. ${ }^{12}$ As against that anaemic mothers ${ }^{11,30,34}$ and underweight mothers increase the risk of childhood anaemia. ${ }^{19}$ Furthermore, children in the age group $12-23$ months $^{12,19,31}$ are at a higher risk of anaemia as compared to other age groups. Underweight children and higher birth order increase the risk of childhood anaemia. $^{12,19,21,31}$

The present study is based on certain assumptions while using the Geographical Information System (GIS) tool. A Geographical 
Table 2

Prevalence of Children Anaemia (6-59 Months) by some selected background Characteristics, NFHS-4, 2015-16.

\begin{tabular}{|c|c|c|c|}
\hline \multicolumn{2}{|c|}{ Background characteristics } & \multirow{2}{*}{$\begin{array}{l}\text { Prevalence of } \\
\text { Anaemia } \\
\mathrm{N}(\%)\end{array}$} & \multirow[t]{2}{*}{ Chi2 -p value } \\
\hline & & & \\
\hline \multicolumn{4}{|c|}{ A. Socio-Economic Characteristics } \\
\hline \multirow[t]{2}{*}{ Place of Residence } & Rural & $32760(56.12)$ & $<0.001$ \\
\hline & Urban & 90115 (59.63) & \\
\hline \multirow[t]{4}{*}{ Religious Group } & Hindu & $97053(58.85)$ & $<0.001$ \\
\hline & Muslim & $20420(59.23)$ & \\
\hline & Christian & $1904(45.8)$ & \\
\hline & Others & $3498(58.84)$ & \\
\hline \multirow[t]{3}{*}{ Social Group } & $S C / S T$ & $41508(61.74)$ & $<0.001$ \\
\hline & OBC & $54514(58.66)$ & \\
\hline & Others & $22007(54.66)$ & \\
\hline \multirow[t]{3}{*}{ Wealth Index } & Poor & $61735(62.16)$ & $<0.001$ \\
\hline & Middle & $24543(59.07)$ & \\
\hline & Rich & 36597 (53.32) & \\
\hline \multirow[t]{6}{*}{ Region } & North & $16988(61.31)$ & $<0.001$ \\
\hline & East & 32366 (59.49) & \\
\hline & North East & $2635(36.87)$ & \\
\hline & Central & 35794 (62.9) & \\
\hline & West & $15065(56.75)$ & \\
\hline & South & $20027(54.45)$ & \\
\hline \multicolumn{4}{|c|}{ B. Maternal Characteristics } \\
\hline \multirow[t]{3}{*}{ Age of Mother } & Less than 25 & 42567 (61.75) & $<0.001$ \\
\hline & $25-35$ & 73349 (57.24) & \\
\hline & 36 and above & $6959(56.01)$ & \\
\hline \multirow[t]{3}{*}{ Mother's Education } & No education & $41383(65.03)$ & $<0.001$ \\
\hline & Primary & $17944(60.65)$ & \\
\hline & Higher & $63548(54.66)$ & \\
\hline \multirow{2}{*}{$\begin{array}{l}\text { Mother's Anaemic } \\
\text { Status }\end{array}$} & No & $45566(50.62)$ & $<0.001$ \\
\hline & Yes & $76946(64.77)$ & \\
\hline \multirow[t]{3}{*}{ Mother BMI } & Thin & 33197 (62.7) & $<0.001$ \\
\hline & Normal & 73233 (58.67) & \\
\hline & Overweight & $16036(51.73)$ & \\
\hline \multirow[t]{2}{*}{ Full ANC } & No & $38787(60.23)$ & $<0.001$ \\
\hline & Yes & $27874(57.28)$ & \\
\hline \multicolumn{4}{|c|}{ C. Child Characteristics } \\
\hline \multirow[t]{2}{*}{ Sex of Child } & Male & 63987 (58.49) & 0.693 \\
\hline & Female & $58888(58.83)$ & \\
\hline \multirow[t]{4}{*}{ Age of Child } & 6 to 11 Years & $15103(68.58)$ & $<0.001$ \\
\hline & 12-23 Months & 33137 (70.58) & \\
\hline & 24-35 Months & $28852(62.37)$ & \\
\hline & 36-59 Months & 45783 (48.57) & \\
\hline \multirow[t]{2}{*}{ Diarrhoea } & No & $110364(58.01)$ & $<0.001$ \\
\hline & Yes & $12372(64.98)$ & \\
\hline \multirow[t]{2}{*}{ Child Nutrition } & Normal & $70416(55.47)$ & $<0.001$ \\
\hline & Underweight & $46751(63.48)$ & \\
\hline \multirow[t]{3}{*}{ Birth Order } & First & $44362(55.6)$ & $<0.001$ \\
\hline & Second & $39366(58.4)$ & \\
\hline & Third \& above & $39147(62.84)$ & \\
\hline
\end{tabular}

Note: N: number; \%: Percentage; Prevalence of Anaemia: Row percentage. Chisquare test: $\mathrm{p}=<.001$ Significant.

Information System is noted to have been utilised in rapid aggregation of multi-source big data and rapid visualization of epidemic information. Such analyses can provide region-specific spatial information which can help in decision-making, policy formulation, and effective assessment of anaemia prevention and control among children. The study findings may be considered with a caution in view of the limitations of the present analysis as it has not covered breastfeeding, vitamin-A supplementation, child immunisation as predictors of childhood anaemia. Such variables may provide further useful insight into the childhood anaemia.

The study showed that religion, social groups, wealth index, region, age of mother, mother's education, mother's anaemic status, mother's BMI, full Antenatal care, diarrhoea suffered by a child, nutritional status and birth orders were significant in occurrence of childhood anaemia.

The study suggests targeting the hot-spot districts with a high prevalence of anaemia in the country. Furthermore, certain important policy
Table 3

Regression Models shows odds of having Anaemia among children (6-59 Months) with Background characteristics.

\begin{tabular}{|c|c|c|}
\hline Background characteristic & & OR $[95 \% \mathrm{CI}]$ \\
\hline \multicolumn{3}{|c|}{ A. Socio-Economic Characteristics } \\
\hline \multirow[t]{2}{*}{ Place of Residence } & Rural ${ }^{\circledR}$ & $1[1.00,1.00]$ \\
\hline & Urban & $0.98[0.95,1.01]$ \\
\hline \multirow[t]{4}{*}{ Religious Group } & Hindu ${ }^{\circledR}$ & $1[1.00,1.00]$ \\
\hline & Muslim & $1.12[1.07,1.17]^{* * *}$ \\
\hline & Christian & $0.83[0.78,0.89]^{* * *}$ \\
\hline & Others & $1.11[1.04,1.19] * *$ \\
\hline \multirow[t]{3}{*}{ Social Group } & $S C / S T \circledast$ & $1[1.00,1.00]$ \\
\hline & $O B C$ & $0.88[0.85,0.91]^{* * *}$ \\
\hline & Others & $0.82[0.79,0.85]^{* * *}$ \\
\hline \multirow[t]{3}{*}{ Wealth Index } & Poor ${ }^{\circledR}$ & $1[1.00,1.00]$ \\
\hline & Middle & $0.97[0.93,1.01]$ \\
\hline & Rich & $0.88[0.84,0.91]^{* * *}$ \\
\hline \multirow[t]{6}{*}{ Region } & North $®$ & $1[1.00,1.00]$ \\
\hline & East & $0.71[0.68,0.74] * * *$ \\
\hline & North East & $0.36[0.34,0.38]^{* * *}$ \\
\hline & Central & $0.92[0.88,0.96]^{* * *}$ \\
\hline & West & $0.79[0.75,0.84] * * *$ \\
\hline & South & $0.76[0.72,0.79] * * *$ \\
\hline \multicolumn{3}{|l|}{ B. Maternal Characteristics } \\
\hline \multirow[t]{3}{*}{ Age of Mother } & Less than 25 ® & $1[1.00,1.00]$ \\
\hline & $25-35$ & $0.89[0.86,0.92]^{* * *}$ \\
\hline & 36 and above & $0.83[0.78,0.88]^{* * *}$ \\
\hline \multirow[t]{3}{*}{ Mother's Education } & No education ${ }^{\circledR}$ & $1[1.00,1.00]$ \\
\hline & Primary & $0.88[0.84,0.92] * * *$ \\
\hline & Higher & $0.77[0.74,0.80] * * *$ \\
\hline \multirow[t]{2}{*}{ Mother's Anaemic Status } & No ${ }^{\circledR}$ & $1[1.00,1.00]$ \\
\hline & Yes & $1.81[1.77,1.86]^{* * *}$ \\
\hline \multirow[t]{3}{*}{ Mother BMI } & Thin ${ }^{\circledR}$ & $1[1.00,1.00]$ \\
\hline & Normal & $0.94[0.91,0.97]^{* * *}$ \\
\hline & Overweight & $0.91[0.87,0.95]^{* * *}$ \\
\hline \multirow[t]{2}{*}{ Full ANC } & $\mathrm{No} \circledast$ & $1[1.00,1.00]$ \\
\hline & Yes & $0.96[0.94,0.99]^{* *}$ \\
\hline \multicolumn{3}{|l|}{ C. Child Characteristics } \\
\hline \multirow[t]{2}{*}{ Sex of Child } & Male ${ }^{\circledR}$ & $1[1.00,1.00]$ \\
\hline & Female & $0.99[0.96,1.01]$ \\
\hline \multirow[t]{4}{*}{ Age of Child } & 6 to 11 Months ${ }^{\circledR}$ & $1[1.00,1.00]$ \\
\hline & 12-23 Months & $1.09[1.05,1.14]^{* * *}$ \\
\hline & 24-35 Months & $0.7[0.67,0.73]^{* * *}$ \\
\hline & 36-59 Months & $0.42[0.40,0.44] * * *$ \\
\hline \multirow[t]{2}{*}{ Diarrhoea } & $\mathrm{No}{ }^{\circledR}$ & $1[1.00,1.00]$ \\
\hline & YeS & $1.03[0.98,1.07]$ \\
\hline \multirow[t]{2}{*}{ Child Nutrition } & Normal ${ }^{\circledR}$ & $1[1.00,1.00]$ \\
\hline & Underweight & $1.29[1.26,1.33]^{* * *}$ \\
\hline \multirow[t]{3}{*}{ Birth Order } & First ${ }^{\circledR}$ & $1[1.00,1.00]$ \\
\hline & Second & $1.05[1.02,1.09] * *$ \\
\hline & Third \& above & $1.12[1.08,1.16]^{* * *}$ \\
\hline $\mathbf{R} 2$ & & 0.08 \\
\hline
\end{tabular}

Note: ${ }^{\circledR}=$ Reference category. ${ }^{*} \mathrm{p}<.10 ;{ }^{* *} \mathrm{p}<.05 ; * * * \mathrm{p}<.01$.

Anaemia: $0=$ not suffered from anaemia, $1=$ suffered from anaemia.

level interventions can be designed based on the determinants of childhood anaemia highlighted by the present study.

\section{Conclusion}

The present study does not only contribute in highlighting remarkable geographical variations in anaemia in India but also examines the contextual factors affecting its occurrence. Based on the findings, the study recommends the public health programmes should target the hot spot districts with the high prevalence of anaemia. Strengthening factors such as mother's education and full ANC along with reducing anaemia among mothers and malnourishment among children can reduce the risk and prevalence of childhood anaemia in India.

The study highlights the need for comprehensive intervention strategies for educating mothers about the harmful impacts of anaemia. The objectives of the existing national programmes such as National 
Nutritional Anaemia Programme (1970), Integrated Child Development Schemes (1975) and Anaemia Mukt Bharat Programme (2018) can ensure better outcomes with focussed strategies targeted at the poor performing regions highlighted by the present study.

\section{Funding sources}

This research did not receive any specific grant from funding agencies in the public, commercial, or not-for-profit sectors.

\section{Author contribution}

Conceptualization: KG \& GD; Data curation: KG; Formal analysis: KG; Funding acquisition: No; Methodology: KG \& GD; Software: KG; Supervision: KG \& GD; Validation: KG \& GD; Visualization: KG; Writing original draft: KG \& GD; Writing - review \& editing: KG \& GD.

\section{Acknowledgement}

No.

\section{References}

1 Kassebaum NJ. The global burden of anemia. Hematol/Oncol Clin. 2016;30(2): 247-308.

2 World Health Oraganisation. The global prevalence of anaemia in 2011. cited 2021 June 7]. Available from http://apps.who.int/iris/bitstream/handle/10665/177094/ 9789241564960_eng.pdf? sequence $=1 ; 2015$.

3 Global nutrition report 2017: Nourishing the SDGs. UNICEF 2017 [cited 2021 June 7 ] Available from https://data.unicef.org/resources/global-nutrition-report-2017-n ourishing-sdgs/; 2017.

4 Lokeshwar MR, Mehta M, Mehta N, Shelke P, Babar N. Prevention of iron deficiency anemia (IDA): How far have we reached? Indian J Pediatr. 2011;78(5):593-602.

5 Haider BA, Olofin I, Wang M, Spiegelman D, Ezzati M, Fawzi WW. Anaemia, prenatal iron use, and risk of adverse pregnancy outcomes: systematic review and metaanalysis. Br Med J. 2013;21:346.

6 Mireku MO, Davidson LL, Koura GK, et al. Prenatal hemoglobin levels and early cognitive and motor functions of one-year-old children. Pediatrics. 2015;136(1): e76-83.

7 Daru J, Zamora J, Fernández-Félix BM, et al. Risk of maternal mortality in women with severe anaemia during pregnancy and post partum: a multilevel analysis. The Lancet Global Health. 2018;6(5):e548-e554.

8 Dubey AP. Iron deficiency anemia epidemiology, diagnosis and clinical profile. In: Sachdev HPS, Choudhury P, eds. Nutrition in Children: Developing Country Concerns. New Delhi: Cambridge Press; 1994:217-235.

9 World Health Organisation. Worldwide prevalence of anaemia 1993-2005: WHO global database on anaemia [cited 2021 June 7] Available from: http://apps. who. int/iris/bitstream/handle/10665/43894/9789241596657_eng.pdf?ua=1; 2008.

10 Pasricha SR, Black J, Muthayya S, et al. Determinants of anemia among young children in rural India. Pediatrics. 2010;126(1):e140-e149.

11 Singh RK, Patra S. Extent of anaemia among preschool children in EAG States, India: a challenge to policy makers. Anemia. 2014;23:2014.

12 Sharma H, Singh SK, Srivastava S. Socio-economic inequality and spatial heterogeneity in anaemia among children in India: evidence from NFHS-4 (2015-16). Clinical Epidemiology and Global Health. 2020;8(4):1158-1171.

13 Dey S, Goswami S, Dey T. Identifying predictors of childhood anaemia in North-East India. J Health Popul Nutr. 2013;31(4):462.
14 Katzman R, Novack A, Pearson H. Nutritional anemia in an inner-city community: relationship to age and ethnic group. J Am Med Assoc. 1972;222(6):670-673.

15 Vazquez-Seoane P, Windom R, Pearson HA. Disappearance of iron-deficiency anemia in a high-risk infant population given supplemental iron. N Engl J Med. 1985;313 (19):1239-1240.

16 Agaoglu L, Torun O, Unuvar E, Sefil Y, Demir D. Effects of iron deficiency anemia on cognitive function in children. Arzneimittelforschung. 2007;57(6):426-430.

17 Zhao A, Zhang Y, Peng Y, et al. Prevalence of anemia and its risk factors among children 6-36 months old in Burma. Am J Trop Med Hyg. 2012;87(2):306-311.

18 Habte D, Asrat K, Magafu MG, et al. Maternal risk factors for childhood anaemia in Ethiopia. Afr J Reprod Health. 2013;17(3):110-118.

19 Bharati S, Pal M, Bharati P. Prevalence of anaemia among 6-to 59-month-old children in India: the latest picture through the NFHS-4. J Biosoc Sci. 2020;52(1): 97-107.

20 Goswmai S, Das KK. Socio-economic and demographic determinants of childhood anemia. J Pediatr. 2015;91(5):471-477.

21 Goswami S, Acharjee R, Dey S. Determinants of anaemia among children aged under five years in Assam, India. International Journal of Contemporary Pediatrics. 2020;7 (11):1.

22 International Institute for Population Sciences. National family health survey (NFHS4), 2015-16 [Cited 2021 June 07]. Available from http://rchiips.org/nfhs/NFHS -4Reports/India.pdf; 2017.

23 International Institute for Population Sciences (IIPS) and ICF. National family health survey (NFHS-4), 2015-16; 2017 India. Cited 2021 June 07]. Available from: http://rchiips.org/nfhs/NFHS-4Reports/India.pdf.

24 Anselin L. Thirty years of spatial econometrics. Pap Reg Sci. 2010;89(1):3-25.

25 Parvin F, Ali SA, Hashmi SN, Ahmad A. Spatial prediction and mapping of the COVID-19 hotspot in India using geostatistical technique. Spatial Information Research. 2021:1-6.

26 Zhang Q, Qin G, Liu Z, et al. Dietary balance index-07 and the risk of anemia in middle aged and elderly people in southwest China: a cross sectional study. Nutrients. 2018;10(2):162.

27 Tariq H, Kamal MU, Reddy P, et al. Anemia, intractable vomiting, chronic diarrhea, and syndrome of inappropriate antidiuretic secretion: a diagnostic dilemma: Disseminated strongyloidosis in a patient with newly diagnosed HTLV infection — case report and review of literature. Medicine. 2017;96(52):9229.

28 Seidelman J, Zuo R, Udayakumar K, Gellad ZF. Caught on capsule: iron-deficiency anemia due to hookworm infection. Am J Med. 2016;129(2):167-169.

29 Okam MM, Koch TA, Tran MH. Iron supplementation, response in iron-deficiency anemia: analysis of five trials. Am J Med. 2017;130(8), 991-e1.

30 Onyeneho NG, Ozumba BC, Subramanian SV. Determinants of childhood anemia in India. Sci Rep. 2019;9(1):1-7.

31 Patel KK, Vijay J, Mangal A, Mangal DK, Gupta SD. Burden of anaemia among children aged 6-59 months and its associated risk factors in India-Are there gender differences? Child Youth Serv Rev. 2021;122:105918.

32 Dutta M, Bhise M, Prashad L, Chaurasia H, Debnath P. Prevalence and risk factors of anemia among children 6-59 months in India: a multilevel analysis. Clinical Epidemiology and Global Health. 2020;8(3):868-878.

33 Rahman MH, Chauhan S, Patel R, et al. Anaemia among Indian children: a study of prevalence and associated factors among 5-9 years old. Child Youth Serv Rev. 2020; 119:105529.

34 Nair KM, Fernandez-Rao S, Nagalla B, et al. Characterisation of anaemia and associated factors among infants and pre-schoolers from rural India. Publ Health Nutr. 2016;19(5):861-871.

35 Nguyen PH, Scott S, Avula R, Tran LM, Menon P. Trends and drivers of change in the prevalence of anaemia among 1 million women and children in India, 2006 to 2016. BMJ global health. 2018;3(5), e001010.

36 Fotso JC, Kuate-Defo B. Socioeconomic inequalities in early childhood malnutrition and morbidity: modification of the household-level effects by the community SES. Health Place. 2005;11(3):205-225.

37 Nguyen PH, Nguyen KC, Le MB, et al. Risk factors for anemia in Vietnam. Southeast Asian J Trop Med Publ Health. 2006 Nov 1;37(6):1213. 